\title{
APPLICATION OF MUTATION TECHNIQUES IN SORGHUM BREEDING FOR IMPROVED DROUGHT TOLERANCE
}

\author{
Soeranto Human, Sihono, Parno \\ Center for the Application of Isotope and Radiation Technology, \\ National Nuclear Energy Agency (BATAN), \\ Jl. Cinere Pasar Jumat, Jakarta, Indonesia
}

\begin{abstract}
APPLICATION OF MUTATION TECHNIQUES IN SORGHUM BREEDING FOR IMPROVED DROUGHT TOLERANCE. Sorghum is not native to Indonesia and has not yet as popular as other cereal crops. This crop has a big potential to be grown and cultivated owing to its wide adaptability and high productivity. Genetic variability of this crop is still low, thus, plant breeding program is required to support sorghum development in the country. The objective is to develop superior genotypes to improve sorghum production and quality, as food, animal feed or for industry. Research on sorghum improvement through induced mutations has been conducted at the Center for the Application of Isotope and Radiation Technology, National Nuclear Energy Agency (BATAN). Durra variety was used as parental material in the breeding program. Induced mutation was made by Gamma irradiation on seed treatments. The optimal radiation dose was to be around 300-500 Gy. Through selection processes and direct screening for drought tolerance, a number of ten putative mutant lines were obtained. In dry season, the mutant lines B-68, B-72, B-95 and B-100 produced grain yield of $4.55,4.50,4.20$ and $4.62 \mathrm{t} / \mathrm{ha}$, respectively. These yields were significantly higher than the original parent Durra (3.50 t/ha) and the control check varieties UPCA (2.68 $\mathrm{t} / \mathrm{ha}$ ) and Higari (3.75 t/ha). These promising mutant lines might be of useful for further sorghum research and development in Indonesia.
\end{abstract}

Keywords: sorghum, induced mutation, mutant lines, drought tolerance.

\section{INTRODUCTION}

Sorghum (Sorghum bicolor L.) is a cereal crop that is usually grown under hot and dry conditions. According to House [1] sorghum might be originated from the headwaters of the Niger River in Africa. Archaeological evidence suggested that the practice of sorghum domestication was introduced from Ethiopia to Egypt about 3000 B.C. Now about $80 \%$ of sorghum cultivation is found in the Africa and Asian regions, however, the world sorghum production is still dominated by the USA, India, Nigeria, China, Mexico, Sudan and Argentina.

In many countries sorghum is generally used as food source, animal feed, and raw materials for industry. According to ICRISAT/FAO [2], as global food source sorghum ranks the fifth after wheat, rice, corn, and barley. A report from U.S. GRAIN COUNCIL [3] mentioned that Grain sorghum is the third most important cereal crop grown in the United States and the fifth most important cereal crop grown in the world. Sorghum grains and stovers (stems and leaves) are mainly used for animal feed and. Sorghum grains are 
also commonly used as raw material for industry such as ethanol, bear, wine, syrup, paint, glue, and modified starch industry [4]. Related to energy source, countries like USA, India and China, have developed sorghum as bioethanol (biofuel). In the USA sorghum can produce up to 10,000 while in China 7,000 and in India 3,000-4,000 liters ethanol/ha/year. In India, an improved, pressurized, multifuel (kerosene, ethanol or diesel) mantle lantern producing light output of 1,250-1,300 lumens (equivalent to that from a $100 \mathrm{~W}$ light bulb) called "Noorie", was developed. A pressurized alcohol stove with a heating capacity of 3 kilowatts for $85 \%$ (v/v) ethanol concentration with a thermal efficiency of 30-50\% was also created [5].

Based on form of its spike and basic spikelet, sorghum is classified into 5 races namely Bicolor, Guenia, Caudatum, Kafir, and Durra. Race Durra having white color of grains is the one that is commonly cultivated as grain sorghum and used as food source. Among race Durra, there is a variety having high sugar content in its stalk, a type what so called sweet sorghum. In many countries, sweet sorghum is used for syrup, sugar (jaggery), and/or ethanol industry $[5,7]$.

Sorghum has a high yield potential, comparable of rice, wheat, and maize. On a field basis, yields have exceeded 11 ton/ha, with above average yields ranging from 7-9 ton/ha where moisture is not a limiting factor. In those areas where sorghum is commonly grown, yields of 3-4 ton/ha are obtained under normal condition [1]. Sorghum is also known to have wide adaptability, ranging from lowland, medium and highland altitude. Highest yields are usually obtained from varieties maturing in 100-120 days. Latematuring varieties tend to be appropriate for forage crop.

Because sorghum is not Indonesian origin, so its genetic variability found in Indonesia is still limited. Some sorghum genotypes have been introduced from abroad e.g. from the International Crop Research Institute for the Semi-Arid Tropics (ICRISAT) in India. Through plant breeding programs, the Ministry of Agriculture has released some sorghum varieties such as UPCA, Keris, Mandau, Higari, Badik, Gadam, Sangkur, Numbu and Kawali [8]. These national varieties have big potential to be cultivated and developed in the arable land in Indonesia especially during wet seasons. Further research on sorghum breeding is needed especially to search for genotypes that can be grown and cultivated during dry seasons.

Sorghum is beleived to have high tolerance to adverse conditions such as drought. Compare to maize, sorghum has a more extensive and fibrous root system. The plant roots penetrate a greater volume of soil to obtain moisture. Fertilizer, even under low rainfall conditions, encourages root development, hence the root are able to extract moisture from a greater volume of soil. Sorghum requires less moisture for growth than some other cereal crops. A study shows that sorghum requires $332 \mathrm{~kg}$ of water per $\mathrm{kg}$ of accumulated dry matter, while maize requires $368 \mathrm{~kg}$ of water, barley $434 \mathrm{~kg}$, 
and wheat $514 \mathrm{~kg}$. Compared to maize, sorghum is also more tolerant to water lodging, salinity, and aluminum toxicity [6].

For the areas having drought problem such as that in Gunungkidul District of Yogyakarta Province, selection of crop species indicating high water use efficiency would be of valuable to be introduced. Sorghum can be the choice since it is thought of having high tolerance to drought [2]. Sorghum breeding to improve its yield in drought prone areas can also be of importance for increasing the overall agricultural production in the region. Its biomass may be used for animal feed while the grains may be used as an alternative food during dry seasons since it has been reported to have good nutrition values [9].

Research on sorghum breeding by using mutation techniques was carried out at the Center for Research and Development of Isotope and Radiation Technology, National Nuclear Energy Agency (BATAN), Indonesia. The objective was to develop superior genotypes to improve sorghum production and quality related it use either as food, animal feed or for industry.

\section{MATERIALS AND METHODS}

Sorghum Durra variety from ICRISAT was used as starting breeding material. The dry seeds with water content of $12 \%$ were irradiated with gamma rays emitted from Cobalt-60 source in the Gamma Chamber 4000A. The dose levels of 0-1000 Gy, with increment of $100 \mathrm{~Gy}$, were used in order to estimate appropriate radiation dose for breeding purposes. Response of sorghum growth in the M1 generation was studied by best-fitting curve software, and the LD-20 and LD-50 values were estimated.

Some M1 plants were harvested to generate of about 4000 M2 plants. Individual plant selections based upon phenotypic variations were started in the segregating M2 population, focusing on agronomic and yield characters. The parental variety Durra and two local varieties (UPCA and Higari) were used as control plants. Screening for drought tolerance used combination of indirect selection (PEG method) and direct selection in the field. In PEG method, concentration of $25 \%$ polyethylene glycol was used and operated in seedling stage. According to Singh and Chaudhary [10], PEG could reduce water potential equivalent to natural drought condition so that water absorption by roots could be affected. In direct selection, the plants were grown directly in drought prone areas during dry season. Sowing time was adjusted to the end of the rainy season. Production of total biomass, yield and its components were used as criteria for selection.

A total number of 170 selected tolerant plants from the PEG method were then transplanted to the field for seed multiplication. Direct drought tolerance test for these selected plants was conducted in the field in Gunungkidul during dry season in 2002 (M4), 2003 (M5), and 2004 (M6), 
respectively. Sowing time was adjusted to around March or April. Artificial irrigation was given only in early growth stage to stimulate seed germination. One month after sowing, the irrigation was stopped and the plants were entirely exposed to the natural drought condition. Condition of average rainfall and rain day at the experimental location is presented in Table 1. Agronomic data of plant height, number of leaves and grain yield were measured and used as criteria for drought tolerance. The growth and yield of the selected drought tolerant plants were also evaluated in the normal field condition during wet season using randomized block design.

Table 1. Average rainfall and rain days during the field trials in Gunungkidul District [11].

\begin{tabular}{|c|c|c|}
\hline \multirow{2}{*}{ Month } & \multicolumn{2}{|c|}{ Average } \\
\cline { 2 - 3 } & Rainfall $(\mathbf{m m})$ & Rain days \\
\hline January & 310.3 & 18 \\
\hline February & 329.0 & 19 \\
\hline March & 280.3 & 15 \\
\hline April & 253.0 & 9 \\
\hline May & 58.6 & 3 \\
\hline June & 67.0 & 4 \\
\hline July & 38.0 & 2 \\
\hline August & 14.1 & 1 \\
\hline September & 6.1 & 1 \\
\hline October & 85.6 & 5 \\
\hline November & 112.8 & 8 \\
\hline December & 201.4 & 15 \\
\hline Total & 1.756 .2 & 100 \\
\hline
\end{tabular}

\section{RESULTS AND DISCUSSION}

The visual effects of gamma irradiation on sorghum seedling growth in the M1 generation are shown in Figure 1. The sigmoid growth curve was studied further by best-fitting model for the relationship between radiation doses and survival rates. It was found that the $3^{\text {rd }}$ degree polynomial fitted the model $(\mathrm{R}=0.9897$, see Figure 2). From this model, it was estimated that the LD-20 = 344 Gy and LD-50 = 504 Gy. This interval doses might be used in determining optimal radiation doses for breeding purposes. For further breeding program, attention should be focused on population derived from the dose within the interval.

Further sorghum breeding was focused on population derived from radiation dose of $400 \mathrm{~Gy}$. From this population, a total number of 170 plants were selected for drought tolerance in seedling stage in the greenhouse. These 170 selected plants were grown in drought prone areas in Gunungkidul 
for direct field test during dry seasons. Through field screening and selection processes in successive generations, ten drought tolerant mutant lines were identified. These mutant lines were B-68, B-69, B-72, B-75, B-83, B-90, B92, B-94, B-95, and B-100. Their agronomic data and yield in dry and wet seasons are presented in Table 2. Some of the mutant lines had agronomic and yield performances significantly better (higher) than that of the original variety (Durra) and the control national check variety (UPCA and Higari). Some visual performances of some mutant lines are presented in Figure 3.

In dry season, a significant increase in grain yield of about $20-30 \%$ compared to the original variety was found in mutant line B-68, B-72, B-95 and B-100 (Table 2). Moreover, B-100 line also had more leaves than the original variety Durra. These results suggested that B-100 was a promising line to be developed as dual purpose sorghum, as grain and forage sorghum, especially when grown in dry season. Since sorghum cultivation are mostly intended only in dry season, thus, the mutant line B-68, B-72, B-95 and B100 are promising to be develop further as new grain sorghum varieties particularly for drought prone areas such as those found in Gunungkidul. All these sorghum mutants have character of white grain color, the type that is desirable for food source. Thus, these promising lines have a good chance to be develop further for alternative food source during dry season, while their stover (stem and leaves) can be used for animal feed.

Table 2 also explains that in general sorghum could grow and yield better in wet season rather than in dry season. In wet season, sorghum line B68 , B-72, B-83, B-90, B-92, B-95 and B-100 produced grain yield of 6.00, $6.21,6.11,5.92,5.87,6.49$ and $6.51 \mathrm{t} / \mathrm{ha}$, respectively. These yields were significantly higher compared to their original variety Durra $(5.00 \mathrm{t} / \mathrm{ha})$ and the local check varieties UPCA (4.34 t/ha). From these data it could be concluded that the mutant line B-68, B-72, B-95 and B-100 were promising to be developed further not only in dry season but also in wet season. Therefore, these promising lines are now included in the national multilocation trials under collaboration with the Ministry of Agriculture.

In dry season, the mutant line B-95 and B-100 had plant height of $160.4 \mathrm{~cm}$ and $160.3 \mathrm{~cm}$ respectively, and significantly shorter than Durra variety. This semi-dwarf stature is an advantage in term of lodging resistance. Focusing on sorghum use for ruminant feed, however, the mutant line B-69, B-90 and B-100 might be appropriately developed further as forage crop because they had higher number of leaves. Forage sorghum could be of important for the local farmers to suffice their animal feeds, thus, it might help them reduce the cost for buying corn leaves.

It is important to keep the promising mutant lines in the sorghum germplasm collection for further breeding program or other research. Some of these promising lines might soon be submitted for official release as new sorghum varieties in Indonesia. Multi location trials of these promising mutant lines were conducted in several Provinces in 2005 and 2006 before 
submission to official release to the Ministry of Agriculture. Cultivation of drought tolerant sorghum would be expected to help farmers increase productivity of their marginal or unproductive land during dry season, so that it would increase the overall agricultural production and ensure food and feed security. Furthermore, sorghum cultivation would also promote land conservation and sustainable agricultural development in the region. Sorghum development program in Indonesia is also aimed to support the government policy in renewable energy source i.e. to develop sorghum for bioethanol. An MOU between BATAN and a private company (LIPPO Enterprises) had been signed in 12 April 2005 for sorghum mutation breeding research. This private company will help BATAN select desirable mutants for industrial purposes.

Table 2. Average agronomic and yield data of the mutant lines and control varieties in wet and dry seasons.

\begin{tabular}{|c|c|c|c|c|c|c|}
\hline \multirow{2}{*}{ Lines } & \multicolumn{3}{|c|}{ Wet Season } & \multicolumn{3}{|c|}{ Dry Season } \\
\hline & PH & NL & $\mathbf{Y i}$ & PH & NL & $\mathbf{Y i}$ \\
\hline B-68 & 179.7 & 8.2 & $6.00 *$ & 164.3 & 7.6 & $4.55^{*}$ \\
\hline B-69 & $187.6^{*}$ & 8.9 & 5.75 & 163.5 & $8.1 *$ & 3.87 \\
\hline B-72 & 175.2 & 8.8 & $6.21 *$ & 166.3 & 7.5 & $4.50 *$ \\
\hline B-75 & $183.5^{*}$ & $9.5^{*}$ & 5.48 & 167.2 & 7.0 & 3.38 \\
\hline B-83 & 177.7 & $9.6^{*}$ & $6.11 *$ & $169.3^{*}$ & 7.9 & 3.83 \\
\hline B-90 & 178.0 & $9.1 *$ & $5.92 *$ & 162.0 & $8.5^{*}$ & 3.22 \\
\hline B-92 & 179.0 & 8.5 & $5.87 *$ & 162.2 & 7.8 & 3.45 \\
\hline B-94 & 177.3 & 9.7 & 5.23 & 162.3 & 7.8 & 3.82 \\
\hline B-95 & 178.8 & 8.5 & $6.49 *$ & $160.4^{*}$ & 7.7 & $4.20 *$ \\
\hline B-100 & $170.6^{*}$ & $9.4^{*}$ & $6.51 *$ & $160.3^{*}$ & $8.5^{*}$ & $4.62 *$ \\
\hline Durra & 175.1 & 8.2 & 5.00 & 165.2 & 7.5 & 3.50 \\
\hline UPCA & 171.9 & 7.5 & 4.34 & 166.0 & 7.1 & 2.68 \\
\hline Higari & 168.1 & 7.7 & 5.60 & 156.7 & 6.5 & 3.75 \\
\hline LSD $5 \%$ & 5.2 & 0.71 & 0.75 & 4.00 & 0.43 & 0.68 \\
\hline
\end{tabular}

*Significantly different compared to the original variety Durra.

$\mathrm{PH}=$ Plant height; $\mathrm{NL}=$ Number of leaves; $\mathrm{Yi}=$ Grain yield $(\mathrm{t} / \mathrm{ha})$ 


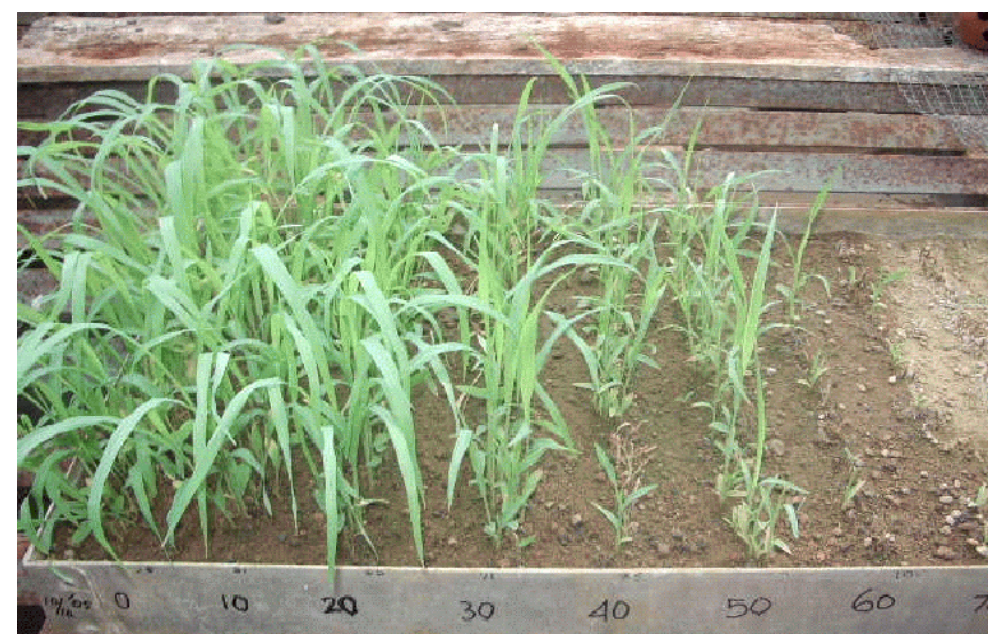

Figure 1. Visual performace of gamma irradiation effects on sorghum growth in the M1 generation.

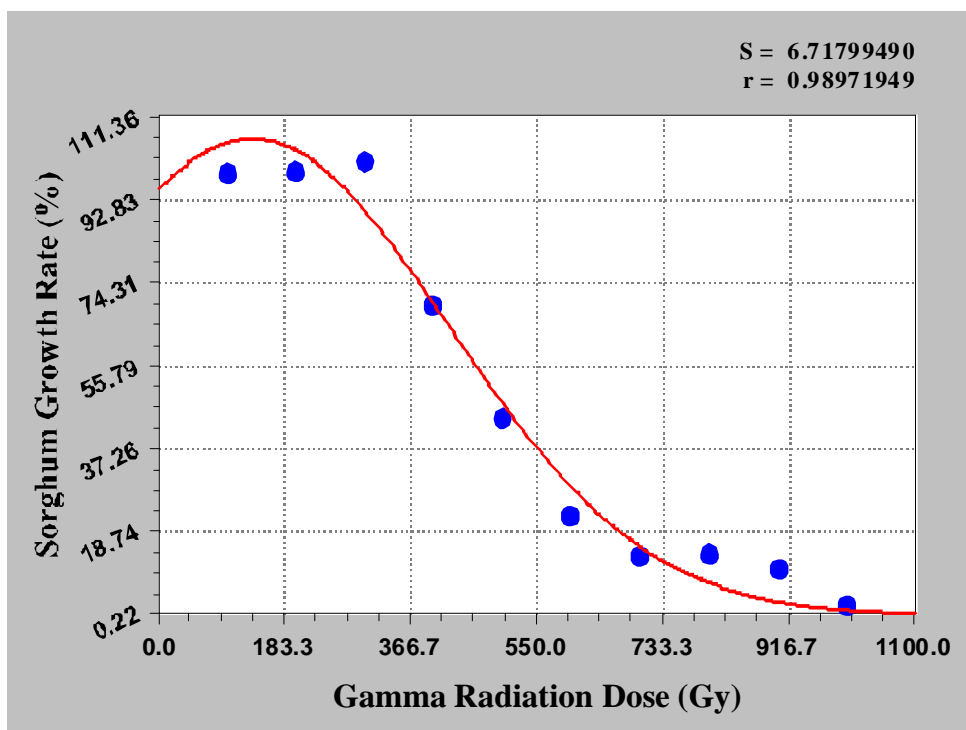

Figure 2. Effect of gamma irradiation on growth rate of sorghum Durra variety in the M1 generation. There was polynomial fit $\mathrm{Y}=\mathrm{a}+\mathrm{bx}$ $+\mathrm{cx}^{2}+\mathrm{dx}^{3}$ with $\mathrm{a}=99.3389, \mathrm{~b}=0.1068, \mathrm{c}=-0.0006$ and $\mathrm{d}=4.2185$. Based on this function, it was estimated that LD$20=344$ Gy and LD-50=504 Gy. 


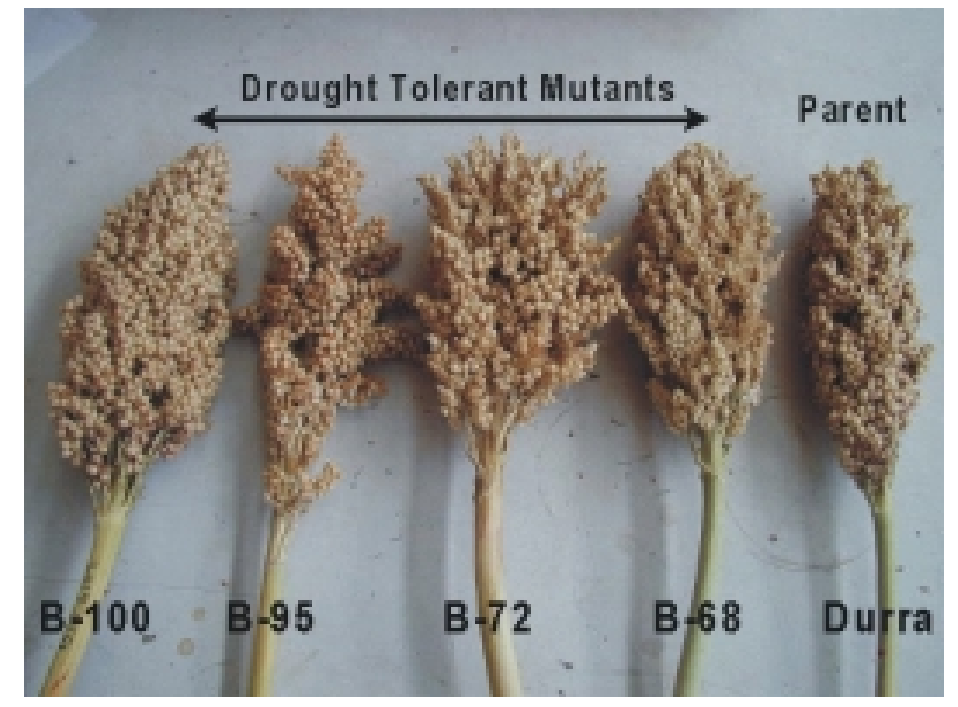

Figure 3. Visual variation on head size and form of some sorghum mutant lines derived from Gamma irradiation with the dose of $400 \mathrm{~Gy}$.

\section{CONCLUSIONS}

Sorghum had a big potential for being used as alternatif food source, animal feed and raw material for industries but it was still neglected. Research on sorghum breeding using mutation techniues was found that the optimal radiation dose of gamma irradiation was to be around 300-500 Gy. Through selection processes and direct screening for drought tolerance, a number of putative mutant lines were obtained. In dry season, the mutant line B-68, B-72, B-95 and B-100 had significant increased in grain yield of about $20-30 \%$ compared to the original variety (Durra). Meanwhile, the mutant line B-69, B-90 and B-100 had more leaves so that they are promising for fodder. These mutant lines were promising to be investigated and developed further in accordance with attempts to increase productivity of marginal land in drought prone areas. Sorghum cultivation in such areas would also promote land conservation and sustainable agriculture development.

\section{ACKNOLEDGMENTS}

We would like to thank IAEA for supporting this sorghum research through IAEA-TC Project INS/5/030 entitled "Sustainable Agriculture Development in Yogyakarta, and through IAEA/RCA Proect RAS/5/040 entitled "Regional Mutant Multi-location Trials and Mutation Enhancement of Genetic Diversity". Also, we would like to thank Forum for Nuclear Co- 
operation in Asia (FNCA) and Japan Society for the promotion of Science (JSPS) for supporting research on drought tolerance in sorghum. All supports from the local counterparts i.e. Ministry of Agriculture, Bogor Agricultural University, Gajah Mada University, and PT. Multi Usaha Wisesa (LIPPO Enterprises) are greatly appreciated.

\section{REFERENCES}

1. HOUSE, L. R.., A Guide to Sorghum Breeding. International Crops Research Institute for Semi-Arid Tropics. Andhra Pradesh, India, 238. (1985).

2. ICRISAT/FAO., The World Sorghum and Millet Economies: Facts, trend and outlook. Published by FAO and ICRISAT. ISBN 92-5103861-9. 68 (1996).

3. U.S. GRAIN COUNCIL., White Sorghum, the New Food Grain. All About White Sorghum (2005).

4. ICRISAT., Industrial Utilization of Sorghum. Proceedings of Symposium on the Current Status and Potential of Industrial Uses of Sorghum, 59 (1990).

5. RAJVANSHI, A.K. and NIMBKAR, N., Sweet Sorghum R \& D at the Nimbkar Agricultural Research Institute (NARI). PO. Box 44, Phaltan 415 523, Maharashtra, India (2005).

6. RANA, B.S. RAO, M.H., Technology for increasing sorghum production and value addition. National Research Center for Sorghum, Indian Council of Agricultural Research. Hyderabad, India, 65 (2000).

7. UNDERSANDER, D.J. et al., Sorghum for syrup. Dept. of Agron. and Soil Sci., Coll. of Agric. and Life Sci., and Cooperative Extension Service, Univ. of Wisconsin-Madison, WI 53706 (1990).

8. DEPTAN., Program Pengembangan Sorgum (Sorghum Development Program). Makalah disampaikan rogram Pengembangan Sorgum, 12 Nov. 2003. Dir. Serealia, Dirjen. Bina Produksi Tanaman Pangan, Departemen Pertanian (Ministry of Agriculture) (2003).

9. DEPKES RI., Daftar Komposisi Bahan Makanan (List of Food Source Composition). Bhratara Publication. Jakarta, 57 (1992).

10. SINGH, B. and CHAUDHARY, L., The physiology of drought tolerance in field crops. Field Crops Research No. 60: 41 - 56 (1998).

11. BPP Semanu., Program penyuluhan pertanian tingkat BPP Kecamatan Semanu. Local Agricultural Extension Program. Published by BPP Semanu, Gunungkidul, Yogyakarta. (Local Agric. Extension Reports). (2005). 